\title{
Can a rhythmic intervention support reading development in poor readers?
}

Professor Susan Hallam, UCL Institute of Education, 20 Bedford Way, London, WC1H OAL s.hallam@ucl.ac.uk

\begin{abstract}
There is increasing interest in the wider benefits of music in relation to reading, although relatively little evidence relating to the role that music might play in developing literacy skills in those experiencing difficulties. The research reported here explores the impact of a rhythmic intervention involving clapping, stamping and chanting to music while following notation on a chart. The intervention took place for 10 minutes each week over a 10 -week period with groups of 10 children, who had lower than average reading scores. The children were in the first year of secondary school (11-12 years old). The Neale Analysis of Reading Ability, second edition (NARA II) test was selected to assess reading accuracy, comprehension and reading rate before and after the intervention with alternative forms of the test being used. 354 pupils attending six secondary schools in the UK participated and were randomly allocated to control (174) and intervention groups (180). Multivariate analysis of variance of change scores across the period of the intervention revealed statistically significant differences between control and intervention groups in reading accuracy $(\mathrm{p}=$ $.014)$ and comprehension $(\mathrm{p}=.001)$ but not in reading rate. The differences in reading accuracy were equivalent to 1.38 standardised scores of progress and reading comprehension to 2.33 standardised scores.
\end{abstract}




\section{Introduction}

There has been extensive research on the role that active engagement with music can have on the development of language skills in young children and the way that it supports the enhancement of phonological awareness and subsequently literacy. Fewer studies have been conducted on the way that music might support improvement in reading for those who are experiencing difficulties, although there has been some research on the role of music in supporting children with dyslexia (Overy, Nicolson, Fawcett and Clarke, 2003). The research reported here focuses on young people experiencing problems with reading who have not been identified as having specific learning difficulties. It explores whether a rhythmic intervention might enhance their readings skills.

\section{The nature of reading development}

Reading development involves dynamic cross-modal processes, beginning with the mapping of letters and sounds, and eventually culminating in skilled reading, which involves the simultaneous processing of phrases, sentences and larger multiple sources of information from the text and their integration with contextually relevant background information from the reader's own experiences (Gellert \& Elbro, 2017; Perfetti \& Stafura, 2014). Reading is a dynamic and multiplex process, a form of phase alignment and is arguably similar to entrainment in musical ensembles, in which individuals segregate and integrate concurrent streams of information (Ragert, Fairhurst and Keller, 2014). Reading requires a form of integrative attending and activates an amodal interface, at which internal and external goals and experiences intersect. 


\section{The relationship between music and language}

There is considerable evidence of a relationship between musical skills and phonological abilities (Slevc and Miyake, 2006). Reading ability and phonological awareness are related to a variety of rhythmic abilities, including reproduction of rhythmic patterns (e.g. Rautenberg, 2015), tempo reproduction (Moritz, Yampolsky, Papadelis et al., 2012); tapping to the beat of music (David, Wade-Woolley, Kirby and Smithrim, 2007); and discrimination of stimuli based on amplitude rise times (see Goswami, Wang, Cruz, et al. 2011; Leong, Hamalainen, Soltesz and Goswami, 2011) and temporal patterns (e.g. Overy, 2003; Strait, Hornickel and Kraus, 2011). Further, children who have language learning impairment tap more variably to a beat (e.g. Corriveau andGoswami, 2009). Musical training improves verbal ability (Moreno, Bialystok, Barac et al., 2011), speech segmentation (François, Chobert, Besson \& Schön, 2013), sentence processing (Moreno, Marques, Santos, et al., 2009) and syllable processing (Chobert, François, Velay and Besson, 2014), while training in beat synchronization has been shown to improve reading fluency (Taub and Lazarus, 2012). Overall, this suggests that rhythmic training may enhance learning to read.

Speech is inherently temporal with boundary lengthening and pauses enhancing the experience of language as a temporal phenomenon (Moberget and Ivry, 2016). The metrical and intonational (pitch) components of grammar are experienced as prosody (Ferreira and Karimi, 2015), regularity determined by the interaction of pitch and rhythm. Jones, Johnston and Puente (2006) have shown that pattern structure, particularly initial patterns of pitch and time, involving small pitch intervals is highly influential, and listeners rely heavily on global pitch structure and rhythm for language processing. 
Tracking rhythm patterns seems to play a vital role in music and speech perception, both important for acquiring reading skills. Beat induction, where humans can derive a pulse from most music even when it is not explicit, has been suggested to serve the development of auditory scene analysis and language (Patel, 2008). In particular, the supplementary motor area (SMA), known to be involved in articulation of speech and the preparation of movement, is also engaged when performing music, imagining listening to music or imagining performing to music (Herholz and Zatorre, 2012; Brown, Zatorre and Penhune, 2015), and plays an important role in planning music segment by segment during performance - both in terms of rhythm and melody sequencing (de Manzanö and Ullén, 2012). The link between the basal ganglia and the SMA along the dorsal route is congruent with the finding that the ability to synchronize with a beat is positively correlated with better pre-reading skills such as segmenting the speech stream and better neural encoding of speech and language (Carr White-Schwoch, Tierney et al., 2014; Tierney \& Kraus, 2014; Slater \& Kraus, 2016), better subcortical neural timing in adolescents (Tierney and Kraus, 2013a) as well as better cognitive and linguistic skills (Tierney and Kraus, 2013b).The integration of sensory and motor information may provide a mechanism for predicting sequence timing (Large, Herrera, and Velasco, 2015), such as the processes that ensure the smooth flow in a conversation.

Two theories are important here. Temporal Sampling Hypothesis proposes a neural mechanism for the tracking of speech amplitude over time (e.g. Goswami, 2011) suggesting phase-locking of slow neural oscillations in the delta and theta range. The mechanism selectively samples low-frequency information in the amplitude envelope which is crucial for the segmentation of speech sounds. Dynamic Attending Theory proposes a similar set of neural oscillators that phase-lock and resonate to the temporal structure of music leading to 
an attentional focus that changes in relation to the rhythmic structure of a piece of music (e.g. Velasco and Large, 2011). Tierney and Kraus (2013c) propose that these theories taken together suggest that rhythm in music and the envelope of speech may be tracked biologically through the same mechanism.

The relationship between language and musical abilities might be explained in relation to signal processing in the dorsal auditory stream which is domain general (putamen, supplementary and pre motor areas as well as parietal areas) suggesting that there is overlap between the perceptual processing of linguistic (Kotz \& Schwartze, 2010; Kotz \& SchmidtKassow, 2015), musical, affective and prosodic sensory information (Fruhholz, Trost and Kotz, 2016). The dorsal circuit integrates auditory and motor processes providing a neural mechanism for speech development, articulation, articulatory sequences and encoding of new vocabulary, phonological short-term memory and feed forward function (Hickok \& Poeppel, 2007; Buchsbaum, Olsen, Koch, \& Berman, 2005). As well as their involvement in initial beat perception involving local gamma band oscillations, the putamen play a pivotal role in the primate and human mCBGT circuit (Merchant et al., 2015), which enables beat perception to be modelled in the pre-SMA where beta band oscillations couple with gammaband oscillations (Fujioka, Ross and Trainor, 2015). Thus a top-down signal enables beat perception and representations of a metrical hierarchy to be driven internally from the motor cortex (Merchant and Barloto, 2017).

\section{The role of enculturation}

Cultural factors play a role in how individuals perceive metrical structure, beat perception (Tierney and Kraus, 2013b) and the perception of complex rhythms (Hannon and Trehub, 2005). By nine months of age, the coordination of rhythm and syllable structure is usually 
sufficiently supportive for the infant to segment the speech stream into syllables (Morgan and Saffran, 1995). Rhythmic movement may play a role in this process. Jones et al. (2006) propose the Pitch/Time Entrainment Theory which argues that timing in the brain can be understood as a response to regular or irregular rhythmical events. Children display entrainment, the patterning of body processes and movements to the rhythm of music, typically by four years of age (Trainor and Cirelli, 2014). It takes longer to adjust to tempo, typically not until seven to eight years of age (Kurgansky and Shupikova, 2011).

Beat synchronization may be enhanced through movement to music. Although the human ability to perceive and entrain to a beat flexibly and accurately is spontaneous and ubiquitous across cultures (Savage, Brown, Sakai and Currie, 2015; Bégel, Benoit, Correa et al., 2017) individual variability in sensorimotor synchronization and beat deafness exists (Nozaradan, Peretz and Keller, 2016). While many children will naturally move in time to a beat, the role of enculturation in this process should not be underestimated (Repp and Su, 2013; Manning and Schutz, 2013).

The process of linguistic and rhythmic enculturation may differ between families from different socio-economic groups. At 18 months of age, children from lower socio-economic status (SES) families have slower responses to highly familiar words in spoken sentences when compared with children from higher SES backgrounds (Fernald, Marchman and Weisleder, 2013). Some children have a weak ability to anticipate upcoming lexical input, as evidenced by an absence of fixation on the target word in a strongly predictive context, perhaps due to poor comprehension (Borovsky, Elman \& Fernald, 2012) or limited production vocabulary (Mani and Heuttig, 2012). Rhythm-based training may enhance awareness of phonemes and syntactic processing as a consequence of improved beat 
perception and entrainment (Jouen, Ellmore and Madden, 2015; Frühholz, Trost and Kotz, 2016), while integrative attending (Ragert et al., 2014; Patel, 2014a) may activate highfeature integration and involvement in sentence comprehension among poor readers (Meyler, Keller, Cherkassky et al., 2007). This could accelerate progress in reading fluency and comprehension among poor readers.

Exploratory research showed that a rhythm-based musical intervention, which involved training participants to read simple musical notation supported students in strengthening reading comprehension and fluency by developing their response to beat perception (Long, 2014; Long and Hallam, 2012). Based on positive educational outcomes for a group of pupils receiving free school meals, it is proposed that this rhythm-based approach could ameliorate the large socioeconomic gap that exists in pupils' reading attainment at the end of primary school (Jerrim, Vignoles, Lingam and Friend, 2015; Ilie, Sutherland, \& Vignoles, 2017). The present study is a larger scale version of the exploratory study and investigates whether a rhythmic intervention supports poor readers, particularly with a focus on maintaining integrative attention while reading musical notation and moving in time with background music. The specific research questions are: Can a rhythm intervention enhance reading skills? Does such an intervention have a greater impact on children's reading when they are from low SES backgrounds?

\section{Methods}

Design: The purpose of the study was to extend earlier exploratory work by deploying a larger sample and a stronger design. The research was quasi-experimental with a control and treatment group. It was carried out in a natural context. 
Ethical issues: The research was carried out in accordance with the ethical procedures of the British Psychological Society and the British Educational Research Association. Parents were informed about the project by the participating schools.

The context: The research was undertaken in an inner London borough, which had a diverse population where 170 languages were spoken. Local authority attainment data (2012) showed that disadvantaged pupils made better progress at primary school than in the secondary phase. The intervention was designed to address this issue, with a focus on enhancing reading. Six secondary schools in the borough participated in the research. The project targeted and recruited pupils who had only just or not achieved national levels at age 11 in reading prior to transfer to secondary school. These levels are determined by the Standards and Testing Agency as part of National Curriculum Assessments. Children are assessed at the end of primary education in English schools that are subject to the School and College Qualifications and Curriculum policy (DfE, 2013).

The sample: Pupils were randomly assigned to treatment or control groups using the National Pupil Database to achieve an even spread of sample characteristics (see Table 1) and for reading attainment across the two groups (see Table 2). There were no statistically significant differences in terms of parental SES as shown by the equal distribution of participants eligible for free school meals in the control and experimental groups. All of the children were in Year 7 (aged 11-12).

Table 1. Features of treatment and control groups following randomised assignment

\begin{tabular}{|l|l|l|l|}
\hline \multirow{2}{*}{ Demographic features } & \multicolumn{3}{|c|}{ Number of pupils } \\
\cline { 2 - 4 } & RFR & Control & Overall \\
\hline Males & 147 & 141 & 288 \\
\hline Females & 62 & 71 & 133 \\
\hline Eligible for free school meals & 70 & 75 & 145 \\
\hline Not eligible for free school meals & 139 & 137 & 276 \\
\hline
\end{tabular}


Table 2. Baseline reading attainment (NARA II) for the overall sample

\begin{tabular}{|l|l|l|l|l|l|l|l|}
\hline Reading ability & Eligible & \multicolumn{2}{l}{ Control } & \multicolumn{2}{l|}{ Intervention } & \multicolumn{2}{l|}{ Overall } \\
\hline $\begin{array}{l}\text { Standardised } \\
\text { scores }\end{array}$ & For FSM & Mean & SD & Mean & SD & Mean & SD \\
\hline \multirow{5}{*}{ Accuracy } & Yes & 89.56 & 11.58 & 93.4 & 9.45 & 91.41 & 10.9 \\
\cline { 2 - 9 } & No & 92.25 & 12 & 91.36 & 11.76 & 91.79 & 11.62 \\
\cline { 2 - 9 } & Overall & 91.34 & 11.99 & 91.98 & 11.13 & 91.67 & 11.55 \\
\hline \multirow{5}{*}{ Comprehension } & Yes & 84.41 & 10.36 & 86.85 & 7.97 & 85.59 & 9.32 \\
\cline { 2 - 9 } & No & 86.87 & 10.15 & 85.01 & 8.86 & 85.9 & 9.53 \\
\cline { 2 - 9 } & Overall & 86.03 & 10.26 & 85.57 & 8.62 & 85.8 & 9.45 \\
\hline & Yes & 97.36 & 11.14 & 100.45 & 9.23 & 98.85 & 10.34 \\
\cline { 2 - 8 } & No & 99.21 & 10.61 & 97.86 & 12.08 & 98.5 & 11.32 \\
\cline { 2 - 8 } & Overall & 98.58 & 10.8 & 89.65 & 11.32 & 98.62 & 11.05 \\
\hline
\end{tabular}

Measures of reading: The NARA II test of reading was selected because it offered:

- A continuous reading scale for pupils between 6 and 12 years of age, spanning transition across primary and secondary level education

- An illustration to accompany each passage of text

- A procedure that allowed pupils to reference the passage when answering comprehension questions.

The NARA II is available in two forms to allow for retesting after a short period of time thereby eliminating the possibility of contaminating pupils' scores due to a degree of familiarity with the test. Form 1 was used for final testing and Form 2 for establishing the baseline. 
The NARA provides normative data via standardised scores and reading age scores for measures of reading accuracy, reading comprehension and reading rate. A reading accuracy score was obtained by counting errors in terms of omitted, added, mispronounced, reversed or substituted words in the reading of each passage. Reading comprehension was measured as the total number of correct responses to questions, posed immediately after the pupil had read the passage of text. Reading rate was calculated by dividing the total number of words read by the total time taken.

The retesting coefficients are very high between Forms 1 and 2 of NARA II on reading accuracy, (0.89) and reading comprehension (0.82), but far lower in terms of reading rate (.66). Internal consistency reliability for Forms 1 and 2 using Cronbach's coefficient alpha is also available for reading accuracy $(0.86 \& 0.87)$ and reading comprehension $(0.93 \& 0.93)$, but not reading rate. Internal consistency reliability was not available for reading rate because during the development of the assessment, pupils' parallel form reliability on reading rate was found to be relatively low (.66) when compared with accuracy (.89) and comprehension (.82) (Neale, 1997)

The intervention: The Rhythm for Reading programme (RFR) is an intensive, systematic and cumulative group intervention programme that aims to accelerate reading attainment by strengthening stability, strength and resilience of cognitive attention. The programme was developed to support a group of disadvantaged, educationally disaffected children, who received free instrumental music lessons because they were eligible for free school meals. Musical resources were commissioned by the programme to capture attention and enhance auditory processing. Rhythmically, the resources representing a relatively narrow range of musical styles, featured simple metrical hierarchies of classical western music, funk, rock and 
pop for the most part, but also included syncopation and metrical complexity in several tracks. The children strengthened integrative attending by learning to clap, chant and stamp their feet in time to the beat of a musical track while following simple musical notation. The simple musical notation included two levels of subdivision of the beat, restricted use of pitch and restricted use of intervals between pitches.

The treatment group received one weekly session of Rhythm for Reading for ten weeks. The sessions were of ten minutes' duration, delivered at a fixed time each week and to groups of ten pupils at a time. Each school provided a room, a laptop and a projector screen for these sessions. There was considerable variation between schools during the intervention period and levels of continuity and consistency during the ten weeks varied in terms of pupils' attendance, punctuality and motivation, availability of ICT equipment and classrooms, as well as changes to agreements regarding days and times of sessions and group sizes.

Data analysis: The NARA II oral reading test data were marked and scored according to the manual for obtaining standardised scores. Baseline and final standardised scores were subtracted to give a 'change score' for reading accuracy, reading comprehension and reading rate representing the change in reading during the ten-week period in which the intervention was delivered. Change scores between the treatment and control groups and pupils' eligibility for free school meals were analysed using multivariate analysis of variance (MANOVA).

\section{Findings}

The mean change in reading accuracy for the intervention group was 1.83 standardised points and for the control group 0.45 standardised points. This difference was statistically significant $\left(\mathrm{F}(1,350)=4.118, \mathrm{p}<0.05 ; \eta \mathrm{p}^{2}=0.012\right)$. The mean change in reading comprehension for the intervention group was 5.82 standardised points and for the control 
group 3.49 standardised points. This difference was statistically significant $(\mathrm{F}(1,350)$ $\left.=10.143, \mathrm{p}<0.01 ; \eta \mathrm{p}^{2}=0.028\right)$. There was no statistically significant difference in rate of reading, which may be related to the lower reliability of this particular aspect of the assessment (see Table 3 \& Figure 1).

Table 3: Mean differences in change scores for control and intervention groups.

\begin{tabular}{|l|l|l|c|c|c|c|c|}
\hline & \multicolumn{2}{|c|}{$\begin{array}{c}\text { Control } \\
\mathrm{N}=174\end{array}$} & \multicolumn{2}{c|}{$\begin{array}{c}\text { Intervention } \\
\mathrm{N}=180\end{array}$} & $\mathrm{df}$ & $\mathrm{F}$ & $\mathrm{p}$ \\
\hline & Mean & $\mathrm{SD}$ & Mean & $\mathrm{SD}$ & & & \\
\hline Change in reading accuracy & .45 & 5.2 & 1.83 & 5.3 & 1,352 & 6.07 & .014 \\
\hline Change in reading comprehension & 3.49 & 6.7 & 5.82 & 6.8 & 1,352 & 10.38 & .001 \\
\hline Change in reading rate & 1.36 & 7.9 & 1.52 & 7.5 & 1,352 & .041 & $\mathrm{NS}$ \\
\hline
\end{tabular}

$$
\text { Control } \mathrm{N}=174 \text { Intervention } \mathrm{N}=180
$$

\section{Figure 1: Comparison of intervention and control groups on NARA test}

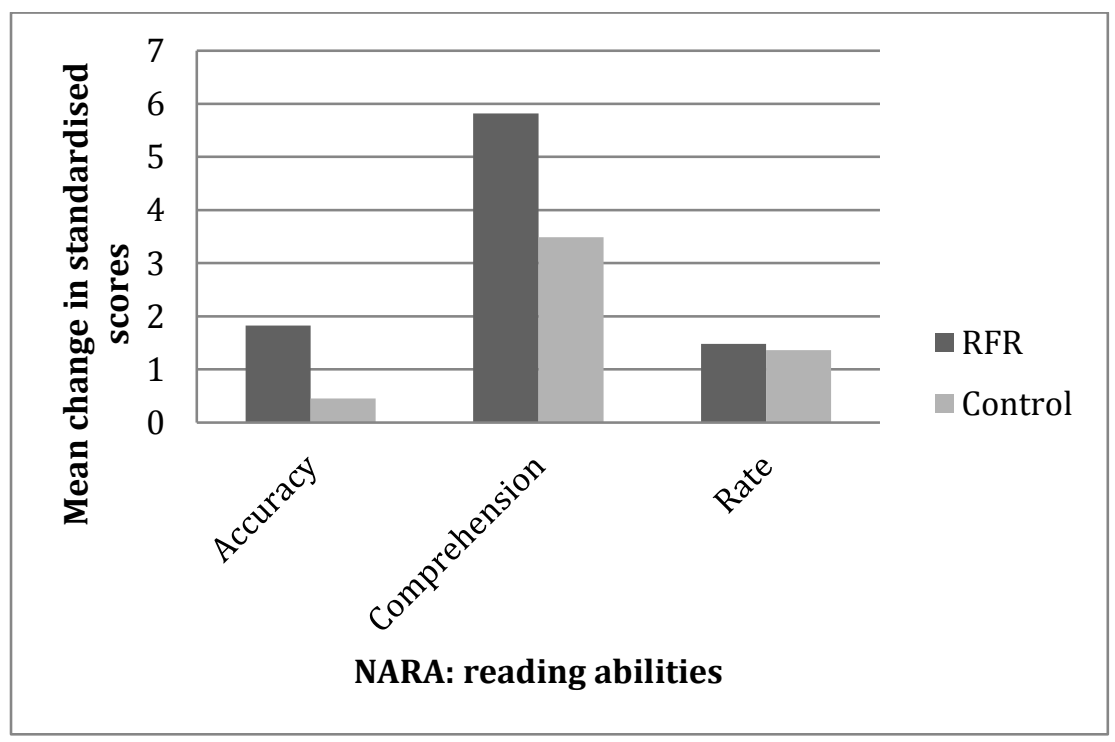

\section{Comparison of pupils' scores eligible for free school meals}

The analysis was extended to consider the extent to which the intervention was successful for children whose families were experiencing financial deprivation and therefore were eligible for free school meals. Multivariate analysis of variance was used to compare the performance of those in the control and experimental groups with eligibility for free school meals. Overall, 
the comparisons were statistically significant $(\mathrm{F}(7,149)=19.87, \mathrm{p}=.0001)$. When individual elements were examined the only statistically significant difference was in reading comprehension. The control group had a change score of 3.96, the intervention group of 6.4 $\left(\mathrm{F}(1,350)=5.141, \mathrm{p}<0.05 ; \eta p^{2}=0.014\right)($ see Table $4 \&$ Figure 2$)$.

Table 4: Mean change standardised scores for pupils eligible for free school meals

\begin{tabular}{|l|c|c|c|c|c|c|c|}
\hline & \multicolumn{2}{|c|}{ Control } & \multicolumn{2}{c|}{ Intervention } & df & F & p \\
\hline & Mean & SD & Mean & SD & 1,155 & & \\
\hline Change in reading accuracy & 1.07 & 5.0 & 1.75 & 6.2 & 1,155 & .57 & NS \\
\hline Change in reading comprehension & 3.96 & 5.9 & 6.4 & 6.9 & 1,155 & 5.6 & .019 \\
\hline Change in reading rate & 1.51 & 6.9 & .54 & 7.0 & 1,155 & .75 & NS \\
\hline
\end{tabular}

Control $\mathrm{N}=81$ Intervention $\mathrm{N}=76$

Figure 2: Comparing NARA mean change scores for pupils with FSM status: RFR group versus Controls for the overall sample

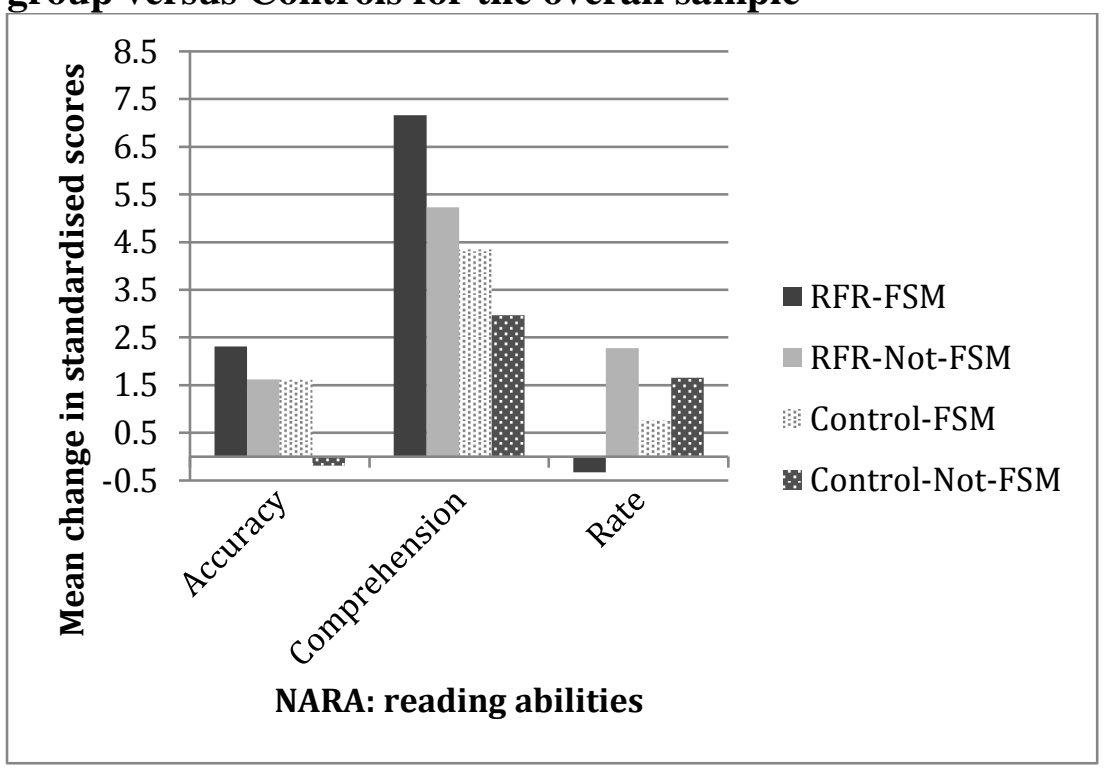

\section{Discussion}

The findings show that statistically significant changes had occurred in pupils' reading of passages of connected text after participation in RFR (ten training sessions of ten minutes).

The RFR group read significantly more accurately than did pupils in the control group. There were also statistically significant gains in reading comprehension for pupils in the RFR group when compared with the control group, indicating that RFR had significantly improved 
pupils' reading comprehension. Reading comprehension gains were significantly larger for disadvantaged pupils. Disadvantaged pupils from the RFR group made the largest gains in reading comprehension overall.

The NARA II consists of six passages of increasing difficulty and is suitable for readers aged 6-12 years of age. The assessment procedure was adhered to at all times: participants first read a passage suitable for a beginner reader and then continued to read passages of increasing difficulty until they had made sixteen accuracy errors in one passage, the cut-off point. The findings showed that the RFR group improved significantly in reading accuracy and comprehension, but not in reading rate. For both groups, reading rate tended to either increase or decrease in relation to baseline scores, due to the difficulty level of passages that participants attempted to read. In general, some pupils read more quickly because their reading accuracy and understanding had improved. However, some pupils who previously had read at a very fast rate and had made frequent errors in accuracy and comprehension, read more slowly in the follow-up assessment. It is likely that they read at a slower pace either because they had become more engaged with the text or because they had encountered unfamiliar words when they progressed onto increasingly difficult passages.

There were no ceiling effects in the data, although seven pupils (1.9\% of the sample) had a reading age of 6 years or lower at the start of the programme. Those with the lower reading age were recorded as having a reading age of six strengthening the validity of the findings. The small effect sizes were influenced by the very broad range in pupils' reading attainment and because one school introduced an intensive individually administered phonics programme for the control group for the ten weeks of the trial period. However, this is typical 
of the type of interventions that schools implement and strengthens the ecological validity of the study.

The significant gains in reading accuracy and reading comprehension for the intervention group confirmed previous findings showing that a rhythm-based intervention significantly improved the reading accuracy and comprehension of poor readers (Long 2014; Long and Hallam, 2012) and findings demonstrating that the ability to synchronize with a beat is positively correlated with better pre-reading skills (Carr et al., 2014; Tierney and Kraus, 2014; Kraus and Slater, 2016), better cognitive and linguistic skills (Tierney and Kraus, 2013b).

The participants were not a uniform group and there was some variation in their response to sensorimotor synchronization (Nozaradan et al, 2016; Grahn and McAuley, 2009). At first, some responded too quickly to the beat, while others responded too slowly. All were able to synchronize with the beat by the end of the intervention period. It is likely that they incurred benefits in language processing and therefore reading skills, having intensively activated a neural overlap (Patel, 2014b). The positive effects of the RFR programme on reading skills are broadly congruent with the conditions for adaptive plasticity set out by Patel (2014b). For instance, the requirement for rhythmic precision in reading musical notation is more explicit and more repetitive than the requirement for rhythmic precision in the perception of spoken utterances or in reading printed language. Perhaps most importantly, the quality of attending demanded by the group activity of entraining to a musical track, whilst stamping their feet, clapping their hands and concurrently reading musical notation simulated the demands of participating in a musical ensemble, that involve integrative attending (Ragert et al., 2014). Integrative attending is a highly demanding form of social entrainment because it requires 
that multiple streams of information processing become aligned between the self and others, forming an interface between goals that are internal and external, and information streams that are endogenous and exogenous.

This intersection of goals and information streams may help to secure reading comprehension among poor readers by compensating for impoverished or incomplete phonological input (see for instance, Meyler et al., 2007; Scharinger, Bendixen, Herrmann, et al., 2016). This is also relevant to the finding that participants in the intervention group who were eligible for free school meals made significantly more progress on reading comprehension than those not eligible. Children from low SES families are known to experience an impoverished auditory environment, are exposed to fewer words in infancy and grow up in homes with fewer or no books (see Skoe et al., 2013; Fernald et al., 2013). The research reported here suggests that musical entrainment can ameliorate some of the effects of social disadvantage on reading development. It is possible that improved sensitivity to rhythm and integrative attending activate a compensatory mechanism, which mitigates incomplete phonological input.

Taking account of the documented decline in Year 7 pupils' motivation levels in core curriculum subjects (Galton, 2009), the Rhythm for Reading programme was delivered to them as if they were 'emergent young adults' (Symonds and Galton, 2014). For example, multi-tasking elements of the programme were contextualised as preparation for learning to drive a car. Students were also told that a locally-based musician with an international career had written the musical resources and had included ideas suggested by pupils of their age and from their neighbourhood. Field notes showed that this approach provoked pupils' interest in the programme. The musical resources were well received by the young people even though some of the music was classical in style. Musical titles and content reflected youth culture, 
such as 'Something Funky' and 'Graffiti Groove' and were appreciated. This was illustrated by comments such as wicked', 'this is well sick' and 'man that's funky' particularly from the boys. Local youth culture was a unifying factor and more influential than were participants' diverse family backgrounds. The resources also resembled tracks of their favourite video games.

The participants also commented on the impact of the programme. After two sessions, one pupil announced that he had finished reading a book for the first time while another wanted to understand how her reading had suddenly improved. After five weeks, many pupils had noticed a change and indicated that their teachers had also seen improvements. They described their reading as 'flowing better', 'more smooth', 'easier to read' and 'clearer'. They had also begun to volunteer to read aloud in class.

One limitation of the research was the consistency with which the intervention was implemented. Only one school ensured that the RFR sessions ran smoothly. In five schools, disruptions were caused by school inspections, staff illness, lack of ICT facilities, room and student availability. In three schools the sessions took place in a room in the Special Educational Needs (SEN) department. Some in the RFR group asked repeatedly why they were there and some opted out of joining in parts of the programme that involved physical coordination. They were anxious about their reputation and did not believe that they had been selected at random. Random assignment to the RFR group seemed to have generated a nocebo effect. Despite these challenges, the intervention supported the development of entrainment in the participants with a subsequent impact on their literacy skills. 


\section{Implications}

The group nature of the entrainment activity may have been important. During the intervention, the participants were subject to consistently high expectations in all aspects of their behaviour, with a particular requirement for high levels of focus and precision in their response to the musical activities. Joint music making maintains a state of tension between a high degree of precision and expectation on the one hand, but also rhythmic flexibility and constant adjustments on the other. This has been described as interpersonal entrainment (Keller et al., 2014; Phillips-Silver \& Keller, 2012). The ability to maintain a simultaneous awareness of self and of others is necessary in even the early stages of novice group musical participation and is likely to have been relevant in the intervention context. This type of social coordination requires a particular attitude, 'integrative attending' (Keller, 1999) which is partly volitional and partly automatic and is determined to some extent by brain state and constant inhibition of the usual levels of self-awareness (Naeem, Prasad, Watson and Kelso, 2012a 2012b). Musical repetition and the predictability of musical structure also support emotional regulation (Rock, Trainor and Addison, 1999). Group participation in musical activities, engages people in cooperative behavior, through joint attention (Trainor and Cirelli, 2015) and their brainwaves are synchronized (Moreno and Bidelman, 2014; Keller, Novembre and Hove, 2014). The RFR intervention may, therefore, have the potential to enhance aspects of social development in the participants.

The findings of the research have implications for music education more generally, particularly in early years and primary education. Co-ordinating movement to a beat, entrainment, plays an important role in the development of reading accuracy and comprehension. While policy makers and head teachers may believe that limited time in school and other resources are better spent in developing children's literacy and numeracy 
directly, this is clearly not successful for some children (Ravitch, 2013). Time allocated for high quality music education which includes support for children in learning to co-ordinate their movements to a beat is likely to have benefits for all children in terms of their literacy in addition to enabling them to develop their musical skills. Further, there is increasing evidence that a programme of musical rhythmic activities also benefits the development of temporal spatial skills and some elements of learning in mathematics (Holmes, 2017).

To conclude, the RFR programme provided students, who previously had poor reading skills, with a structured framework which allowed them to develop sensitivity to beat perception, rhythmic awareness and integrative attending, resulting in a significant improvement in their reading accuracy and comprehension. Participants from disadvantaged backgrounds made significantly more progress than their peers, indicating that impoverishment can be mitigated through this approach. The findings also suggested that the RFR programme was sufficiently resilient to withstand the challenges that can arise in school settings and that it is important for young children to engage in active music making.

Acknowledgements: The research was funded by the Education Endowment Foundation $(\mathrm{EEF})$

\section{References}

Bégel, V., Benoit, C. E., Correa, A., Cutanda, D., Kotz, S. A., \& Dalla Bella, S. (2017). "Lost in time" but still moving to the beat. Neuropsychologia, 94, 129-138.

Borovsky, A., Elman, J. L., \& Fernald, A. (2012). Knowing a lot for one's age: Vocabulary skill and not age is associated with anticipatory incremental sentence interpretation in children and adults. Journal of Experimental Child Psychology, 112(4), 417-436.

Brown, R. M., Zatorre, R. J., \&Penhune, V. B. (2015). Expert music performance: cognitive, neural, and developmental bases. Progress in brain research, 217, 57-86.

Buchsbaum, B. R., Olsen, R. K., Koch, P. \& Berman, K. F. (2005) Human dorsal and ventral auditory streams subserve rehearsal-based and echoic processes during verbal working memory. Neuron 48, 687-697. 
Brown, R. M., Zatorre, R. J., \&Penhune, V. B. (2015). Expert music performance: cognitive, neural, and developmental bases. Progress in brain research, 217, 57-86.

Carr, K.W., White-Schwoch, T., Tierney, A.T. Strait, D.L. \& Kraus, N. (2014). Beat synchronization predicts neural speech encoding and reading readiness in pre-schoolers. Proceedings of the National Academy of Sciences, 111(40), 14559-14564

Chobert, J., François, C., Velay, J. L., \& Besson, M. (2014). Twelve months of active musical training in 8-to 10-year-old children enhances the pre-attentive processing of syllabic duration and voice onset time. Cerebral Cortex, 24(4), 956-967.

Corriveau, K.H. \& Goswami, U. (2009) Rhythmic motor entrainment in children with speech and language impairments: tapping to the beat. Cortex, 45(1), 119-130.

David, D. Wade-Woolley, L., Kirby J.R., \& Smithrim, K. (2007). Rhythm and reading development in school-aged children: a longitudinal study. Journal of research in reading, 30(2), 169-183.

De Manzanö, O.\& Ullén, F. (2012). Activation and connectivity patterns of the presupplementary and dorsal premotor areas during free improvisation of melodies and rhythms. Neuroimage 63, 272-280.

Department for Education (2013) The National Curriculum in England: Key Stages 1 and 2 frameworkdocument. Available at: https://www.gov.uk/government/publications/nationalcurriculum-in-england-primary-curriculum.

Fernald, A., Marchman, V. A., \& Weisleder, A. (2013). SES differences in language processing skill and vocabulary are evident at 18 months. Developmental Science, 16, 234248.

Ferreira, F., \&Karimi, H. (2015). Prosody, performance, and cognitive skill: Evidence from individual differences. In L. Frazier \& E. Gibson (Eds.) Explicit and implicit prosody in sentence processing: Studies in honor of Janet Dean Fodor (pp. 119-132). Switzerland: Springer International Publishing

François. C., Chobert, J., Besson, M. \& Schön, D. (2013). Music training for the development of , W., \& Kotz, S. A. (2016). The sound of emotions-Towards a unifying neural network perspective of affective sound processing. Neuroscience \& Biobehavioral Reviews, 68, 96110.

Frühholz, S., Trost, W., \& Kotz, S. A. (2016). The sound of emotions-Towards a unifying neural network perspective of affective sound processing. Neuroscience \& Biobehavioral Reviews, 68, 96-110.

Fujioka T, Ross B, Trainor LJ (2015) Beta-band oscillations represent auditory beat and its metrical hierarchy inperception and imagery. J Neurosci 35(45):15187-15198

Galton, M. (2009). Moving to secondary school: initial encounters and their effects. Perspectives on Education 2 (Primary-secondary Transfer in Science), 5-21. 
Gellert, A. S., \& Elbro, C. (2017). Does a dynamic test of phonological awareness predict early reading difficulties? A longitudinal study from Kindergarten through grade 1. Journal of learning disabilities, 50(3), 227-237.

Goswami, U. (2011) A temporal sampling framework for developmental dyslexia. Trends in Cognitive Science, 15(1), 3-10.

Goswami, U., Wang, H-L. S., Cruz, A., Fosker, T., Mead, N. \& Huss, M. (2011). Languageuniversal sensory deficits in developmental dyslexia: English, Spanish and Chinese, Journal of cognitive neuroscience, 23(2), 325-337.

Grahn J. A. \& McAuley J. D. (2009). Neural bases of individual differences in beat perception. Neuroimage 47(4), 1894-903.

Hannon, E. E.\&Trehub, S. E. (2005). Tuning in to musical rhythms: Infants learn more readily than adults. Proceedings of the National Academy of Sciences USA, 102, 1263912643.

Herholz, S.C.\& Zatorre, R.J., (2012). Musical training as a framework for brain plasticity: behavior, function, and structure. Neuron 76, 486-502.

Hickok, G., \&Poeppel, D. (2007). The cortical organization of speech processing. Nature Reviews Neuroscience, 8(5), 393-402.

Holmes, S. (2017) The impact of participation in music on learning mathematics. Unpublished PhD thesis. London: Institute of Education, UCL.

Ilie, S. Sutherland, A., Vignoles, A. (2017) Revisiting free school meal eligibility as a proxy for pupil socio-economic deprivation, British Educational Research Journal, 43, 2, 253-274

Jerrim, J., Vignoles, A., Lingam, R., \& Friend, A. (2015). The socio- economic gradient in children's reading skills and the role of genetics. British Educational Research Journal, 41(1), 6-29.

Jones, M.R., Johnston, H.M. \& Puente, J. (2006). Effects of auditory pattern structure on anticipatory and reactive attending. Cognitive psychology, 53, 59-96.

Jouen, A. L., Ellmore, T. M., Madden, C. J., Pallier, C., Dominey, P. F., \& Ventre-Dominey, J. (2015). Beyond the word and image: characteristics of a common meaning system for language and vision revealed by functional and structural imaging. NeuroImage, 106, 72-85.

Keller, P.E. (1999) Attending in complex musical interactions: the adaptive dual role of meter. Aust. J. Psychol., 51, 166-175.

Keller, P. E., Novembre, G., \& Hove, M. J. (2014). Rhythm in joint action: psychological and neurophysiological mechanisms for real-time interpersonal coordination. Phil. Trans. R. Soc. B, 369(1658), 20130394. 
Kotz, S. A., \& Schwartze, M. (2010). Cortical speech processing unplugged: A timely subcortico-cortical framework. Trends in Cognitive Sciences, 14, 392-399.

doi:10.1016/j.tics.2010.06.005

Kotz, S.A. \& Schmidt-Kassow, M. (2015). Basal ganglia contribution to rule expectancy and temporal predictability in speech. Cortex, 68, 48-60.

Kurgansky, A.V. \& Shupikova, E.S. (2011) Visuo-motor synchronisation in adults and seven to eight year old children. Human Physiology, 37,526,

https://doi.org/10.1134/s0362119711050100

Large, E. W., Herrera, J. A., \& Velasco, M. J. (2015). Neural networks for beat perception in musical rhythm. Frontiers in systems neuroscience,

9.https://doi.org/10.3389/fnsys.2015.00159

Leong, H., Hamalainen, J., Soltesz, F. \& Goswami, U. (2011). Rise time perception and detection of syllable stress in adults with developmental dyslexia. Journal of Memory and Language, 64(1), 59-73.

Long, M. (2014). 'I can read further and there's more meaning while I read': An exploratory study investigating the impact of a rhythm-based music intervention on children's reading, Research Studies in Music Education, 36(1), 99-116.

Long, M. \& Hallam, S. (2012) Rhythm for Reading: A rhythm-based approach to reading intervention, Proceedings of Music Paedeia: From Ancient Greek Philosophers Toward Global Music Communities, pp. 221-232, 30 ${ }^{\text {th }}$ ISME World Conference on Music Education, 15-20 July, 2012, Thessaloniki, Greece.

Mani, N., \& Huettig, F. (2012). Prediction during language pro- cessing is a piece of cake but only for skilled producers. Journal of Experimental Psychology: Human Perception and Performance, 38(4), 843-847.

Manning, F., \&Schutz, M. (2013). "Moving to the beat" improves timing perception. Psychonomic bulletin \& review, 20(6), 1133-1139.

Merchant, H., \& Bartolo, R. (2017). Primate beta oscillations and rhythmicbehaviours. Journal of Neural Transmission, 1-10.

Merchant, H., Grahn, J., Trainor, L., Rohrmeier, M., \& Fitch, W. T. (2015). Finding the beat: a neural perspective across humans and non-human primates. Phil. Trans. R. Soc. B, 370(1664), 20140093.

Meyler, A., Keller, T. A., Cherkassky, V. L., Lee, D., Hoeft, F., Whitfield-Gabrieli, S., ... \& Just, M. A. (2007). Brain activation during sentence comprehension among good and poor readers. Cerebral Cortex, 17(12), 2780-2787.

Moberget, T. \& Ivry, R. B. (2016), Cerebellar contributions to motor control and language comprehension: searching for common computational principles. Annals of the New York Academy of Sciences, 1369, 154-171. 
Moreno, S., Marques, C., Santos, A., Santos, M., Castro, S. L. \& Besson, M. (2009). Musical training influences linguistic abilities in 8-year-old children: More evidence for brain plasticity. Cereb Cortex. 19(3),712-723.

Moreno, S., Bialystok, E., Barac, R., Schellenberg, E. G., Cepeda, N. J., Chau, T. (2011). Short-term music training enhances verbal intelligence and executive function. Psychological Science, 22,1425-1433

Moreno, S., \& , G. M. Bidelman (2014). Examining neural plasticity and cognitive benefit through the unique lens of musical training. Hearing research, 308, 84-97.

Morgan, J. L., \& Saffran, J. R. (1995). Emerging integration of sequential and suprasegmental information in preverbal speech segmentation. Child development, 66(4), 911-936.

Moritz, C. Yampolsky, S., Papadelis, G., Thomson, J. \& Wolf, M. (2012) Links between early rhythm skills, musical training and phonological awareness. Reading and writing, 26(5), 739-769.

Naeem, M., Prasad, G., Watson, D. R., Kelso, J. A. S. (2012a). Electrophysiological signatures of intentional social coordination in the 10-12 Hz range.Neuroimage 59, 17951803.

Naeem, M., Prasad, G., Watson, D.R. \& Kelso, J.A.S. (2012b). Functional dissociation of brain rhythms in social coordination.Clin. Neurophysiol., 123, 1789-1797

Neale, M. D. (1997). Neale Analysis Of Reading Ability - Revised. Windsor: NFER-Nelson

Nozaradan, S., Peretz, I. \& Keller, P. E. (2016).Individual Differences in Rhythmic Cortical Entrainment Correlate with Predictive Behavior in Sensorimotor Synchronization. Sci. Rep.6, 20612; doi: 10.1038/srep20612.

Overy, K., Nicolson, R.I., Fawcett, A.J. \& Clarke, E.F. (2003). Dyslexia and music: Measuring musical timing skills. Dyslexia, 9(1), 18-36.

Patel, A.D. (2008). Beat-based rhythm processing as a key research area, In A.D. Patel. Music, Language and the Brain (pp. 402-415). Oxford: Oxford University Press.

Patel A.D. (2014a). The Evolutionary Biology of Musical Rhythm: Was Darwin Wrong? PLoS Biol 12(3): e1001821 doi:10.1371/journal.pbio.1001821.

Patel, A. D. (2014b). Can nonlinguistic musical training change the way the brain processes speech? The expanded OPERA hypothesis. Hearing Research, 308, 98-108.

Perfetti, C. \& Stafura, J. (2014) Word knowledge in a theory of reading comprehension. Scientific Studies of Reading, 18, 22-37.

Phillips-Silver, J., \& Keller, P.E. (2012). Searching for roots of entrainment and joint action in early musical interactions. Front. Hum. Neurosci., 6, 26. 
Ragert, M., Fairhurst, M. T., \& Keller, P. E. (2014). Segregation and integration of auditory streams when listening to multi-part music. PloS one, 9(1), e84085.

Ravitch, D. (2013). Reign of Error: The Hoax of the Privatization Movement and the Danger to America's Public Schools. New York: Alfred A. Knopf.

Rautenberg, I. (2015) The effects of musical training on the decoding skills of Germanspeaking primary school children. Journal of research in reading, 38(1), 1-17.

Repp, B.H, \& Su, Y.H. (2013). Sensorimotor synchronization: a review of recent research (2006-2012). Psychon. Bull. Rev. 20, 403-452.

Rock, A.M.L.,Trainor, L.J. \&Addison, T. (1999).Distinctive messages in infant-directed lullabies and playsongs. Dev. Psychol., 35,527-534

Savage, P. E., Brown, S., Sakai, E., \& Currie, T. E. (2015). Statistical universals reveal the structures and functions of human music. Proceedings of the National Academy of Sciences, 112(29), 8987-8992.

Scharinger, M., Bendixen, A., Herrmann, B., Henry, M. J., Mildner, T., \& Obleser, J. (2016). Predictions interact with missing sensory evidence in semantic processing areas. Human brain mapping, 37(2), 704-716.

Skoe, E., Krizman, J., \& Kraus, N. (2013). The impoverished brain: disparities in maternal education affect the neural response to sound. Journal of Neuroscience, 33(44), 1722117231.

Slater, J \& Kraus, N. (2016) The role of rhythm in perceiving speech in noise: a comparison of percussionists, vocalists and non-musicians. Cognitive processing, 17(1), 79-87.

Slevc, L.R. \& Miyake, A. (2006). Individual differences in second-language proficiency. Psychol Sci. 17(8), 675-681.

Strait, D. L. Hornickel, J. \& Kraus, N. (2011). Subcortical processing of speech regularities underlies reading and music aptitude in children. Behaviour and brain function, 7(1), 44. https://doi.org/10.1186/1744-9081-7-44

Symonds, J. E., \& Galton, M. (2014). Moving to the next school at age 10-14 years: An international review of psychological development at school transition. Review of Education, 2(1), 1-27.

Taub, G.E. \& Lazarus, P.J. (2012) The effects of training in timing and rhythm on reading achievement. Issues in Education, 5(4), 343-350.

Tierney, A., \& Kraus, N. (2013a). The ability to move to a beat is linked to the consistency of neural responses to sound. The Journal of Neuroscience, 33(38), 14981-14988.

Tierney A.T. and Kraus, N. (2013b). The ability to tap to a beat relates to cognitive, linguistic, and perceptual skills. Brain Lang., 124,225-231. 
Tierney, A, \& Kraus, N, (2013c) Music training for the development of reading skills. In M.M.Merzenich, M. Nahum \& T.M. Van Vleet (eds) Progress in Brain Research, vol 207. Burlington: Academic Press (pp 209-241).

Tierney, A. and Kraus, N. (2014) Auditory-motor entrainment and phonological skills: precise auditory timing hypothesis (PATH). Frontiers in Human Neuroscience, 8(949), doi:10.3389/fnhum.2014.00949

Trainor, L.J., \& Cirelli, L. (2015). Rhythm and interpersonal synchrony in early social development.Annals of the New York Academy of Sciences, 1337(1), 45-52.

Velasco, M.J. \& Large, E.W. (2011). Pulse detection in syncopated rhythms using neural oscillators. Paper presented at the $12^{\text {th }}$ annual conference of the International Soceity for Music Information retrieval. (October, Miami) http://ismire2011.ismirt.net/papers/PS2-3.pdf. Retrieved 09-08-17. 